\title{
ECOLOGY
}

\section{Diversity and stability in plant communities}

\author{
Arising from: D. Tilman, P. B. Reich \& J. M. H. Knops Nature 441, 629-632 (2006)
}

The relationship between species diversity and ecosystem stability is controversial ${ }^{1,2}$. Tilman et al. ${ }^{3}$ analyse biomass patterns over a decade in a grassland experiment with artificial plant communities, and provide evidence for a positive relationship between the number of plant species and the temporal stability of the ecosystem. Here we use data from a long-term biodiversity experiment with plant communities that were not controlled by weeding ${ }^{4}$ in order to show that diverse systems can be both stable and unstable.

In 1996, we established plant communities by sowing low-diversity (4 species) and high-diversity ( 15 species) seed mixtures, and compared the development of the plant communities with those of unsown plots ${ }^{4}$. After sowing, by contrast with other diversity tri$\mathrm{als}^{3,5}$, plots were not weeded so that subsequent development of the plant community was due to natural colonization and plant-community assemblage processes. In the following nine years, plant diversity and above-ground biomass were higher in plots sown with 15 , rather than 4 , species (Fig. 1a-c). The results were the same when we excluded the initial years after sowing, which excludes the possibility that the starting conditions caused the observed effects (Table 1). Increasing the seed-mixture diversity enhanced biomass production, as in plant communities in which diversity was maintained by hand-weeding ${ }^{3,5}$. However, the richness and diversity of the species were consistently highest in non-sown plots, which had the lowest biomass production (Fig. 1a-c; Table 1).

Temporal stability, based on biomass production $^{3}$, was lowest in the non-sown plots and highest in plant communities that were initially sown with 15 species (Fig. 1d). The stability of individual species was also lowest in non-sown plots. Annual rates of extinction and colonization were higher in non-sown than in sown plots, and in plots sown with 4 species rather than 15 species (Fig. 1e,f; Table 1).

Most plant species occurred in all plots, but at different densities. A total of 58 plant species were recorded, with cover being greater than or equal to $1 \%$ per square metre on at least one sampling occasion. Of these, only four species were recorded exclusively in some of the nonsown plots and one in plots sown with four species. In almost all cases, those species were rare locally and did not contribute significantly to biomass production (see Methods). Moreover, the observed differences in the rates of extinction and colonization could not be attributed to the presence or absence of those species.

Temporal stability was not related to species
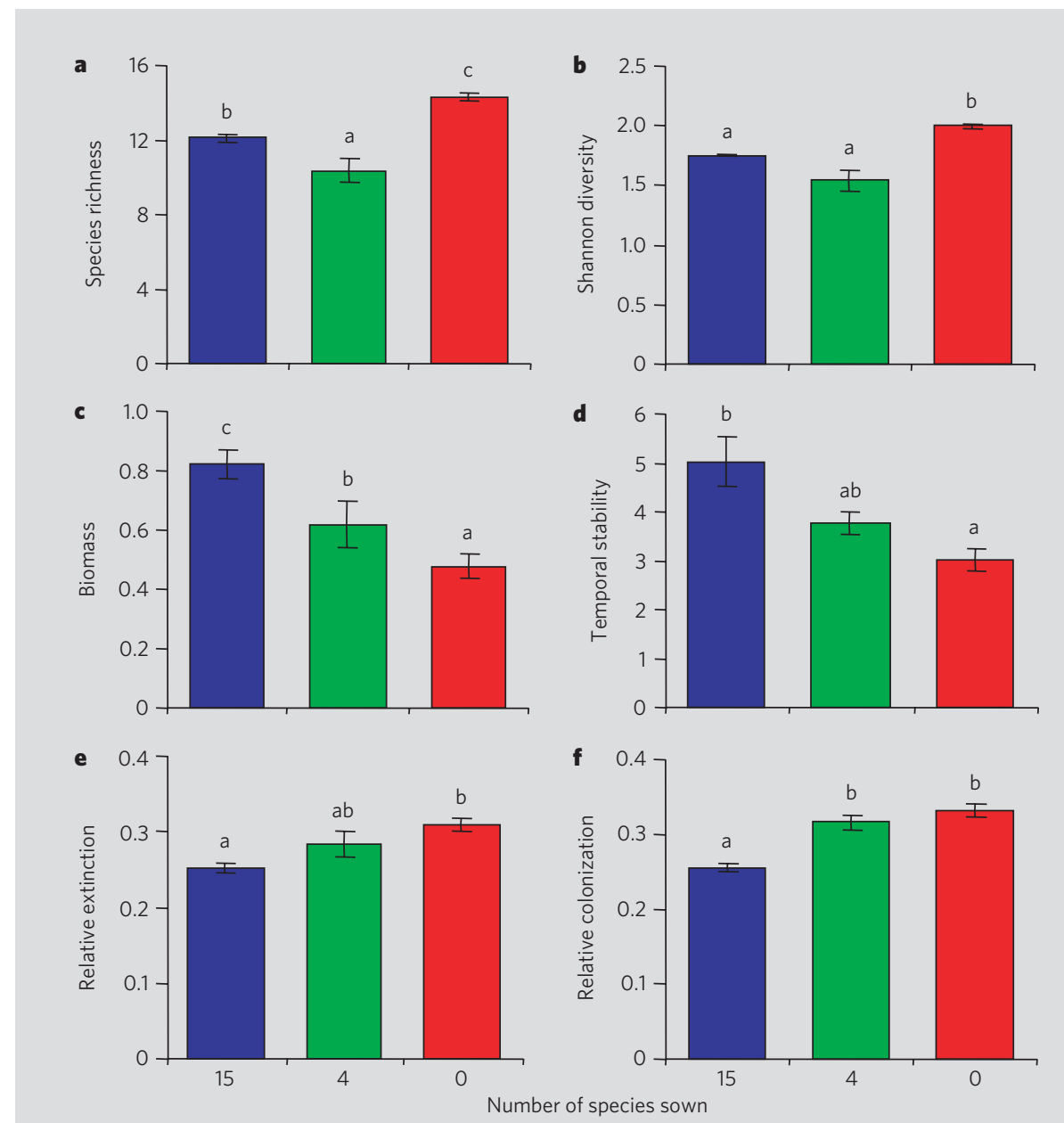

Figure 1 | Initial seed-diversity level (15, 4 or 0 species) determines long-term ecosystem characteristics in unweeded grassland plots. Means for 1997-2005 are shown ( \pm s.e.) for: a, species richness (number per square metre); b, Shannon diversity; c, above-ground biomass (kilograms per square metre); d, temporal stability (calculated as the mean biomass of each plot over the study period, divided by the standard deviation for that period); e, relative annual extinction rate (number of species in $1-\mathrm{m}^{2}$ subplots going extinct between two subsequent years, divided by mean number of species present in those two years); and $f$, relative annual colonization rate (number of species in $1-\mathrm{m}^{2}$ subplots colonizing between two subsequent years, divided by the mean number of species present in those two years). Within in each panel, letters above bars indicate significant differences $(P<0.05)$ between individual sowing treatments $(0,4,15$ species), based on a Tukey HSD test after the 'between' analysis (see Table 1).

richness, but there was a positive relationship with biomass $(r=0.62)$, whereas productivity was negatively related to extinction $(r=-0.89)$ and colonization rates $(r=-0.68)$. Biomass, in turn, was strongly positively related to legume abundance $(r=0.82)$, which was lowest in non-sown plots. Legume abundance therefore strongly influences relationships between diversity and functioning in plant communities, as in artificially assembled communities ${ }^{6}$

Our results show that a long-term positive relationship between biodiversity and ecosystem stability also occurs in plant communities that have not been weeded after sowing. However, in the non-sown, completely self-assembled plant communities, we found that high species diversity coincided with low temporal stability, and high extinction and colonization. We conclude that diversity-stability relationships are strongly context dependent.

Methods. Experimental plots were 100 $\mathrm{m}^{2}$, with five replicate plots per diversity treatment (15, 4 or 0 species sown). After sowing, plots were not weeded, but aboveground biomass was removed annually in 
September. Abundance of individual plant species and above-ground biomass were recorded annually in 12 permanent subplots. Data (averaged per plot) were analysed for the period 1997-2005, thereby omitting the establishment year (1996). For further information, see www.nioo.knaw.nl/ppages/mbezemer/.

\section{T. Martijn Bezemer ${ }^{\star}+$ t,}

\section{Wim H. van der Putten ${ }^{\star} \uparrow$}

*Department of Multitrophic Interactions, Netherlands Institute of Ecology, PO Box 40, 6666 ZG Heteren, the Netherlands

† Laboratory of Nematology, Wageningen University and Research Centre, PO Box 8123, 6700 ES Wageningen, the Netherlands e-mail: martijn.bezemer@wur.nl YLaboratory of Entomology, Wageningen University and Research Centre, PO Box 8031 $6700 \mathrm{EH}$ Wageningen, the Netherlands

Received 15 June 2006; accepted 27 February 2007.

1. Lehman, C. L. \& Tilman, D. Am. Nat. 156, 534-552 (2000).

2. Pfisterer, A. B. \& Schmid, B. Nature 416, 84-86 (2002).

3. Tilman, D., Reich, P. B. \& Knops, J. M. H. Nature. 441, 629-632 (2006)

4. Fukami, T., Bezemer, T. M., Mortimer, S. R. \& van der Putten, W. H. Ecol. Lett. 8, 1283-1290 (2005).

5. Hector, A. et al. Science 286, 1123-1127 (1999).

6. Hooper, D. U. et al. Ecol. Monogr. 75, 3-35 (2005).

Competing financial interests: declared none. doi:10.1038/nature05749
Table $1 \mid$ Results of repeated measures analysis of variance (ANOVA) ( $F$ and $P$ values)

\begin{tabular}{|c|c|c|c|c|}
\hline & \multicolumn{2}{|c|}{ Between effect } & \multicolumn{2}{|c|}{ Time $\times$ treatment interaction } \\
\hline & $F$ & $P$ & $F$ & $P$ \\
\hline \multicolumn{5}{|l|}{ Test for $0,4,15$ species } \\
\hline Species richness & 20.60 & 0.0005 & 2.56 & 0.004 \\
\hline Shannon diversity & 18.87 & 0.0009 & 5.64 & $<0.0001$ \\
\hline Above-ground biomass & 42.33 & $<0.0001$ & 1.65 & 0.08 \\
\hline Temporal stability & 8.28 & 0.01 & & \\
\hline Relative colonization rate & 38.66 & $<0.0001$ & 8.07 & $<0.0001$ \\
\hline Relative extinction rate & 9.75 & 0.007 & 2.79 & 0.0032 \\
\hline \multicolumn{5}{|l|}{ Test for 4,15 species } \\
\hline Species richness & 7.33 & 0.05 & 3.03 & 0.01 \\
\hline Shannon diversity & 5.44 & 0.07 & 8.32 & 0.0002 \\
\hline Above-ground biomass & 23.03 & 0.009 & 0.58 & 0.8 \\
\hline Temporal stability & 6.29 & 0.07 & & \\
\hline Relative colonization rate & 40.26 & 0.003 & 6.09 & 0.0002 \\
\hline Relative extinction rate & 4.16 & 0.1 & 2.99 & 0.02 \\
\hline \multicolumn{5}{|c|}{ Test for sown, non-sown plots } \\
\hline Species richness & 15.19 & 0.003 & 2.53 & 0.02 \\
\hline Shannon diversity & 16.60 & 0.003 & 4.73 & 0.0001 \\
\hline Above-ground biomass & 15.41 & 0.003 & 2.82 & 0.009 \\
\hline Temporal stability & 8.19 & 0.02 & & \\
\hline Relative colonization rate & 4.61 & 0.06 & 5.36 & $<0.0001$ \\
\hline Relative extinction rate & 8.91 & 0.02 & 1.54 & 0.2 \\
\hline
\end{tabular}

Between effects are independent of time, whereas the time $x$ treatment interaction tests for differences in the response of treatments over the period 1997 to 2005 . Three tests were carried out: one that compared all three sowing treatments, one that compared the two diversity levels of sown plots, and one that compared sown with unsown plots. Temporal stability was calculated over the whole time period and was analysed with ANOVA. To obtain normality, data were log-transformed before analysis when appropriate. The effect of sowing diversity (4 versus 15 species) remains significant for species richness and Shannon diversity when the first three years after establishment (1997-99) are omitted from the analyses.

\section{ECOLOGY}

\section{Tilman et al. reply}

Replying to: T. M. Bezemer \& W. H. van der Putten Nature 446, doi: 10.1038/nature05749 (2007)

Bezemer and van der Putten ${ }^{1}$ observe that greater initial plant diversity is associated with greater productivity (total above-ground plant biomass), greater ecosystem temporal stability and greater stability of plant community composition (that is, lower per-species extinction and colonization rates). Their results are consistent with the results of our biodiversity experiment ${ }^{2}$ and with predictions of theor $y^{3}$, but with an intriguing twist.

In their study, initial plant diversity (number of species sown) had a strong and long-lasting effect on ecosystem productivity (biomass) and temporal stability (see their Fig. $1 \mathrm{c}, \mathrm{d}$ ), whereas the number of species acquired through natural community assembly seems to have no consistent effect on productivity and ecosystem stability. In particular, if the species-richness data of their Fig. 1a are used as the independent variable and the associated data on biomass (their Fig. 1c) and temporal stability (their Fig. 1d) as dependent variables, the resulting graphs indicate that there is no relationship between assembled species richness and these two variables.

Why might initial planted diversity matter, but not the diversity that results from subsequent community invasion during assembly? Field experiments that have controlled for both plant species number and species composition by use of randomized designs have shown that both diversity and composition are significant determinants of productivity $^{4-6}$ and temporal stability ${ }^{2}$. Bezemer and van der Putten ${ }^{1}$ do not control for species composition but rather allow natural community assembly to determine composition and, ultimately, the number of plant species, which confounds diversity and composition. They reported earlier that the assembly process did not lead to convergent compositions, and that compositions of their three seeding treatments (seeding plots with 0,4 or 15 species) remained as different after nine years as they had been after their first year of growth ${ }^{7}$.

It seems likely that many of the species that invaded the unsown plots were early successional species, and so may have been better colonists but poorer competitors, with lower nutrient-use efficiencies than the sown species. If so, rather than clouding earlier results, their results reinforce the concept that ecosystem functioning depends just as much on which species are present as on how many are present. The two experiments are hence easily reconciled - in our experiment, diversity effects were examined while holding composition neutral, whereas composition effects swamped the diversity effect in the experiments of Bezemer and van der Putten ${ }^{1}$.

Additionally, their results offer an insight into restoration ecology. Planting a disturbed site with a higher number of native, late successional species (their 15-species treatment) led to greater productivity and to greater temporal stability than did planting fewer such species (their four-species treatment), which, even after nine years, had a similar advantage over the unrestored (unsown) plots that were undergoing succession. More complete restoration caused better ecosystem functioning. It will be interesting to see, if the experiment continues, if or when the three treatments converge in their productivity and temporal stability.

David Tilman ${ }^{\star}$, Peter B. Reich Johannes Knops:

*Department of Ecology, Evolution and Behavior, 
and $†$ Department of Forest Resources, University of Minnesota, St Paul, Minnesota 55108, USA e-mail: tilman@umn.edu

$\Varangle$ School of Biological Sciences, University of Nebraska, Lincoln, Nebraska 68588-0118, USA
1. Bezemer, T. M. \& van der Putten, W. H. Nature 446, doi: 10.1038/nature05749 (2007).

2. Tilman, D., Reich, P. B. \& Knops, J. M. H. Nature $\mathbf{4 4 1 ,}$ 629-632 (2006).

3. Lehman, C. L. \& Tilman, D. Am. Nat. 156, 534-552 (2000).

4. Tilman, D. et al. Science 294, 843-845 (2001)

5. Hooper, D. U. et al. Ecol. Monogr. 75, 3-35 (2005).
6. Reich, P. B. et al. Proc. Natl Acad. Sci. USA 101, 10101-10106 (2004).

7. Fukami, T., Bezemer, T. M., Mortimer, S. R. \& van der Putten, W. H. Ecol. Lett. 8, 1283-1290 (2005).

doi: $10.1038 /$ nature 05750 